\title{
Detection of Coronary Artery Disease in Patients with a Permanent Pacemaker
}

\author{
Jan-Peter van Kuijk ${ }^{a}$ Tabita M. Valentijn ${ }^{b}$ Willem-Jan Flu ${ }^{a}$ Don Poldermans ${ }^{a}$ \\ ${ }^{a}$ Department of Vascular Surgery, Erasmus MC, Rotterdam, and ${ }^{b}$ Department of Cardiology, \\ St. Antonius Ziekenhuis, Nieuwegein, The Netherlands
}

Cardiac pacing has been used in the treatment of bradyarrhythmia for more than 50 years, and throughout that time period both clinical practice and an impressive amount of research have objectively proven its effectiveness. Especially in the last decade the number of patients treated with a permanent pacemaker implantation has increased, and due to the aging of the population this number continue to grow [1]. Importantly, the prevalence of coronary artery disease (CAD) in these patients is high and most patients will develop symptoms suggestive of angina pectoris. As a consequence, the use of noninvasive testing has increased in these vulnerable subjects to prevent additional invasive assessment or intervention. Noninvasive methods for the detection and diagnosis of CAD in patients with a permanent pacemaker, recommended by the American College of Cardiology/American Heart Association (ACC/AHA) guidelines, include adenosine or dipyridamole perfusion imaging and dobutamine stress echocardiography [2]. However, in the last decade studies have demonstrated pitfalls and weaknesses of these imaging modalities in patients with a permanent pacemaker [3-6]. Single-photon emission computed tomography (SPECT) with either thallium or technetium is routinely used for ischemia detection, but in patients with a pacemaker perfusion defects that were not related to obstructive CAD have been demonstrated $[3,6]$. False- positive defects are mainly observed in the inferoposterior, inferior, and apical myocardium, which could be explained by differences in regional blood flow during ventricular pacing [4]. Importantly, these perfusion abnormalities are more prominent during physical exercise compared with pharmacological stress using dipyridamole or adenosine [5].

Stress echocardiography is usually performed using pharmacological stressors such as dobutamine or dipyridamol. Dobutamine stress echocardiography has been extensively studied in patients undergoing noncardiac surgery [7]. Through the infusion of dobutamine, positive chronotropic and inotropic effects increase myocardial oxygen consumption. In pacemaker-dependent patients, wall motion abnormalities are present because of an altered ventricular activation; consequently, the interpretation of dobutamine stress echocardiography can be misleading. Furthermore, Ciaroni et al. [8] suggested that the presence of chronotropic incompetence may reduce the accuracy of dobutamine stress echocardiography.

Pacing stress echocardiography (PASE) using atrial pacing through the esophagus has been successfully used since the 1980s for the detection and risk stratification of CAD [9]. Importantly, in contrast to dobutamine stress echocardiography, PASE only has positive chronotropic effects and no inotropic effects. Modi et al. [10] summa-

\section{KARGER}

Fax +41613061234 E-Mail karger@karger.ch www.karger.com
(C) 2010 S. Karger AG, Base

0008-6312/10/1163-0226\$26.00/0

Accessible online at:

www.karger.com/crd
Don Poldermans, MD

Department of Vascular Surgery, Erasmus Medical Center

's-Gravendijkwal 230, room H805

NL-3015 CE Rotterdam (The Netherlands)

Tel. +31 10703 4613, Fax +31 10703 4957, E-Mail d.poldermans@erasmusmc.nl 
rized studies on PASE and reported a sensitivity between 79 and $95 \%$ and a specificity between 71 and $100 \%$. In addition, they observed an accuracy of $90 \%$ for PASE in the detection of CAD compared with standard coronary angiography. Recently, a novel method for cardiac pacing was introduced which uses PASE with a permanent pacemaker.

In this issue of Cardiology, Shimoni et al. [11] describe the results of their study in which an evaluation was made between the diagnostic accuracy of PASE compared with dypiridamol thallium-201 SPECT. A group of 58 patients with a permanent pacemaker and known or suspected CAD was studied. Both PASE and SPECT were performed in $53(91 \%)$ patients, and the concordance in terms of a positive test result was $75 \%$, with a $\kappa$ value of 0.64 . The sensitivity and specificity of PASE were 87 and $78 \%$ compared with 96 and 57\% for SPECT. Before the present study, several small single-center studies tested the ability of PASE for the detection of CAD [12-14]. A comparison between these studies has limitations, as none of them used the same stress and pacing protocols. Overall, the sensitivity and specificity of PASE ranged from 77 to 96 and from 68 to 88\%, respectively, depending on gender and age [14]. The authors observed a concordance of $75 \%(\kappa=0.64)$ between PASE and SPECT in detecting CAD. A $\kappa$ value between 0.61 and 0.80 means that there is substantial concordance between the 2 tests.

In addition to the testing results, Shimoni et al. [11] described the prognostic value of PASE in patients with a permanent pacemaker. During a widely distributed follow-up period of 51 months (range 3-68 months), 8 cardiac deaths occurred and 24 cardiac events were observed. Multivariate regression analyses showed that only positive PASE was associated with the occurrence of cardiac events. Although these results seem to be in line with previous results of larger studies [14, 15], they need to be interpreted with caution due to the limited number of patients and cardiac events in the present study.

In summary, Shimoni et al. [11] describe the value of a novel noninvasive technique in the cardiac evaluation of elderly patients with a permanent pacemaker. Compared with SPECT, the use of PASE has acceptable sensitivity and specificity for the detection of CAD in these patients. Although the concordance between PASE and SPECT regarding a positive test result is substantial, it is important to acknowledge the fact that PASE and SPECT are intrinsically different techniques. Whereas in SPECT myocardial perfusion is studied, PACE is directed at wall motion abnormalities. Expected advantages of PASE are that it is cost-effective, radiation-free, and less time-consuming than SPECT. Major limitations of the present study include: (1) a nonrandomized design, (2) PASE and SPECT were not both performed in all patients, and (3) coronary angiography was not routinely performed. In conclusion, this study demonstrated that PASE is a promising novelty for detecting ischemia in pacemaker-dependent patients, but further evaluation is required in prospective, randomized, comparative studies.

\section{References}

1 Vardas PE, Auricchio A, Blanc JJ, Daubert JC, Drexler H, Ector H, Gasparini M, Linde C, Morgado FB, Oto A, Sutton R, Trusz-Gluza M: Guidelines for cardiac pacing and cardiac resynchronization therapy: The Task Force for Cardiac Pacing and Cardiac Resynchronization Therapy of the European Society of Cardiology. Developed in collaboration with the European Heart Rhythm Association. Eur Heart J 2007;28:2256-2295.

-2 Gibbons RJ, Balady GJ, Beasley JW, Bricker JT, Duvernoy WF, Froelicher VF, Mark DB, Marwick TH, McCallister BD, Thompson PD Jr, Winters WL, Yanowitz FG, Ritchie JL, Gibbons RJ, Cheitlin MD, Eagle KA, Gardner TJ, Garson A Jr, Lewis RP, O’Rourke RA, Ryan TJ: ACC/AHA Guidelines for Exercise Testing: a report of the American College of Cardiology/American Heart Association Task Force on Practice Guidelines (Committee on Exercise Testing). J Am Coll Cardiol 1997;30:260-311.
-3 Skalidis EI, Kochiadakis GE, Koukouraki SI Chrysostomakis SI, Igoumenidis NE, Karkavitsas NS, Vardas PE: Myocardial perfusion in patients with permanent ventricular pacing and normal coronary arteries. J Am Coll Cardiol 2001;37:124-129.

-4 Ten Cate TJ, Van Hemel NM, Verzijlbergen JF: Myocardial perfusion defects in right ventricular apical pacing are caused by partial volume effects because of wall motion abnormalities: a new model to study gated myocardial SPECT with the pacemaker on and off. Nucl Med Commun 2009;30:480484.

5 Ten Cate TJ, Visser FC, Panhuyzen-Goedkoop NM, Verzijlbergen JF, van Hemel NM: Pacemaker-related myocardial perfusion defects worsen during higher pacing rate and coronary flow augmentation. Heart Rhythm 2005;2:1058-1063.
-6 Tse HF, Lau CP: Long-term effect of right ventricular pacing on myocardial perfusion and function. J Am Coll Cardiol 1997;29: 744-749.

7 Poldermans D, Arnese M, Fioretti PM, Salustri A, Boersma E, Thomson IR, Roelandt JR, van Urk H: Improved cardiac risk stratification in major vascular surgery with dobutamine-atropine stress echocardiography. J Am Coll Cardiol 1995;26:648-653.

$\checkmark 8$ Ciaroni S, Bloch A, Albrecht L, Vanautryve B: Diagnosis of coronary artery disease in patients with permanent cardiac pacemaker by dobutamine stress echocardiography or exercise thallium-201 myocardial tomography. Echocardiography 2000;17:675-679.

-9 Atar S, Nagai T, Cercek B, Naqvi TZ, Luo H, Siegel RJ: Pacing stress echocardiography: an alternative to pharmacologic stress testing. J Am Coll Cardiol 2000;36:1935-1941. 
-10 Modi SA, Siegel RJ, Birnbaum Y, Atar S: Systematic overview and clinical applications of pacing atrial stress echocardiography. Am J Cardiol 2006;98:549-556.

$\checkmark 11$ Shimoni S, Goland S, Livshitz S, Arditi A, Ayzenber O, Kusniec F, Gendelman G, Edri O, Lutati G, Levi R, Caspi A, Epstein M: Accuracy and long-term prognostic value of pacing stress echocardiography compared with dipyridamole TI201 emission computed tomography in patients with a permanent pacemaker and known or suspected coronary artery disease. Cardiology 2010;116: 229-236.
2 Benchimol D, Mazanof M, Dubroca B, Benchimol H, Bernard V, Couffinhal T, Dartigues JF, Roudaut R, Pillois X, Bonnet J: Detection of coronary stenoses by stress echocardiography using a previously implanted pacemaker for ventricular pacing: preliminary report of a new method. Clin Cardiol 2000;23:842-848.

13 Picano E, Alaimo A, Chubuchny V, Plonska E, Baldo V, Baldini U, Pauletti M, Perticucci R, Fonseca L, Villarraga HR, Emanuelli C, Miracapillo G, Hoffmann E, De Nes M: Noninvasive pacemaker stress echocardiography for diagnosis of coronary artery disease: a multicenter study. J Am Coll Cardiol 2002; 40:1305-1310.
4 Plonska-Gosciniak E, Lancellotti P, Kleinrok A, Gackowski A, Gasior Z, Kowalik I, Gozdzik A, Kasprzak JD: Influence of gender on diagnostic accuracy of rapid atrial and ventricular pacing stress echocardiography for the detection of coronary artery disease: a multicenter study (Pol-RAPSE final results). J Am Soc Echocardiogr 2008;21:11161120.

15 Biagini E, Schinkel AF, Elhendy A, Bax JJ, Rizzello V, van Domburg RT, Krenning BJ, Schouten O, Branzi A, Rocchi G, Simoons ML, Poldermans D: Pacemaker stress echocardiography predicts cardiac events in patients with permanent pacemaker. Am J Med 2005;118:1381-1386. 